\title{
A Study of HELLP Syndrome among Cases of Pre-Eclampsia and Eclampsia: Incidence and Correlation of Laboratory Parameters
}

\author{
Priyadarshini Tiwari1 $^{*}$, Sona Bhalavi ${ }^{1}$, Shubhangi Nayak ${ }^{2}$, Rajesh Tiwari² \\ ${ }^{1}$ Department of Obstetrics and Gynecology, NSCB Medical College, Jabalpur, India \\ ${ }^{2}$ Department of Community Medicine, NSCB Medical College, Jabalpur, India \\ Email: ${ }^{\text {drpriya2004@yahoo.co.in }}$
}

Received 17 August 2015; accepted 3 September 2015; published 8 September 2015

Copyright (C) 2015 by authors and OALib.

This work is licensed under the Creative Commons Attribution International License (CC BY). http://creativecommons.org/licenses/by/4.0/

(c) (i) Open Access

\begin{abstract}
Objective: To determine the incidence of HELLP syndrome amongst cases of Eclampsia and severe pre-eclampsia admitted to our hospital and to study the correlation of laboratory parameters with the mean arterial pressure (MAP) and with each other. Method: 238 cases of severe pre-eclampsia and eclampsia were studied for their clinical features, laboratory parameters and outcome. Cases were divided into two groups: non HELLP and complete HELLP for comparison of the maternal and perinatal outcome. The levels of Alanine Transaminase (ALT) were compared against other laboratory parameters for correlation. The mean arterial pressures (MAP) of the patients were computed to investigate whether its levels had any correlation with the derangement of ALT. Statistical analysis was done in SPSS software and spearman's correlation was run for the laboratory parameters. Results: No significant difference was seen in the maternal and perinatal mortality in the two groups. ALT showed no correlation with MAP as with LDH, platelets and hemoglobin and a weak but significant correlation with the parameters of renal function. Conclusion: Our population shows a low incidence of HELLP syndrome; the hepatic dysfunction correlates with the renal dysfunction without any correlation with the MAP.
\end{abstract}

\section{Keywords}

HELLP, Pre-Eclampsia, Eclampsia, Microangiopathy, Hemolysis, Genetic

Subject Area: Gynecology \& Obstetrics

\section{Introduction}

Pre-eclampsia is a vaso constrictive disease occurring in pregnancy and manifests as hypertension, edema and

${ }^{*}$ Corresponding author.

How to cite this paper: Tiwari, P., Bhalavi, S., Nayak, S. and Tiwari, R. (2015) A Study of HELLP Syndrome among Cases of Pre-Eclampsia and Eclampsia: Incidence and Correlation of Laboratory Parameters. Open Access Library Journal, 2: e1853. http://dx.doi.org/10.4236/oalib.1101853 
proteinurea. When this is accompanied by convulsions, the disorder is known as eclampsia. The basic pathology of these disorders originates in the placenta and delivery leads to a reversal of the pathology. Eclampsia occurs commonly in the young primigravida due to immunological causes and in the elderly multipara due to underlying hypertensive disorders.

The syndrome of hemolysis with elevated liver enzymes and low platelet count was given the name HELLP syndrome by Weinstein in 1982. It is generally encountered as a complication or a variety of severe pre-eclampsia but may also occur independent of severe pre-eclampsia [1]. 10\% to $20 \%$ cases of severe pre-eclampsia may exhibit the features of HELLP syndrome [2] [3]. The criteria for HELLP syndrome (Mississippi criteria 2006) require a) evidence of hemolysis, demonstrated by a peripheral smear showing schistocytes or burr cells, elevation of unconjugated bilirubin or LDH level $\geq 600 \mathrm{IU}$, b) ALT levels $\geq 70 \mathrm{IU}$, and c) platelet count below $150,000 / \mathrm{ml}$. For the diagnosis of complete HELLP, all three criteria are required whereas partial HELLP requires only one or two elements for diagnosis.

HELLP syndrome has to be differentiated from other thrombotic microangiopathies. Other conditions with thrombotic microangiopathy are Hemolytic uremic syndrome (HUS), Thrombotic Thrombocytopenic Purpura (TTP) and Systemic Lupus Erythematosis (SLE) [4]. The atypical variety of HUS may occur in adults who have a history of diarrhea and fever in the recent past [5]. They show a severe derangement of renal functions and rapidly falling platelet counts. TTP is a rare disorder with predominantly neurological manifestations [6]. Patients with HELLP syndrome show improvement and reversal of symptoms after delivery which are not seen in other disorders.

There is hardly any role of conservative management once the diagnosis of eclampsia is established. For severe pre-eclampsia and HELLP syndrome $<34$ weeks, corticosteroid therapy to accelerate fetal lung maturation prior to termination of pregnancy may be given [7]. The choice of the route of delivery is whether abdominal or vaginal depends on the indication as well as the available infrastructure in the institution. Delivery leads to amelioration of the symptoms with improvement of the clinical and biochemical parameters.

\section{Methodology}

238 cases of eclampsia and severe pre-eclampsia admitted to our hospital in a period of 14 months were included in the study. The clinical features and lab parameters of all these patients were noted. Their platelet count and liver functions were noted. LDH values were taken to denote evidence of hemolysis. Platelet count $<$ $150,000, \mathrm{ALT} \geq 70 \mathrm{IU}$ and $\mathrm{LDH} \geq 600 \mathrm{IU}$ were taken to denote complete HELLP syndrome. Patients were classified according to the Mississippi criteria (2006) [8]. The mean arterial pressure was computed. Maternal and perinatal mortality in the HELLP and non HELLP group was computed and compared to look for any statistically significant difference. The laboratory parameters were studied for any correlation with the MAP and with each other. Analysis was done using SPSS software. The derangement of ALT (alanine transaminase) was the parameter showing the most remarkable elevation in our study population and we tried to find out how and if it correlated with the derangement of the other laboratory parameters. A Spearmann's correlation was the statistical test applied to determine the correlation of other variables with the levels of ALT.

In statistics, statistical significance (or a statistically significant result) is attained when a $p$-value is less than the significance level. The $p$-value is the probability of obtaining at least as extreme results given that the null hypothesis is true. As a matter of good scientific practice, a significance level was chosen before data collection and was set to $0.05(5 \%)$.

The study was undertaken with the approval of the ethics committee of our institution. The study was done after taking informed consent from all the patients.

Class 1 HELLP were patients with platelet count $\leq 50,000 / \mathrm{ml}$ with ALT $\geq 70$ IU and LDH $\geq 600$ IU. Class 2 HELLP were patients with platelet count between 50,000 and $100,000 / \mathrm{ml}$, rest of the criteria being the same. Class 3 were patients with platelet count between 100,000/ml and 150,000/ml and ALT $\geq 40 \mathrm{IU} / \mathrm{ml}$.

\section{Results}

According to this classification, a total of eight patients out of 238 fulfilled the criteria of HELLP syndrome. Out of these, two were cases of severe pre-eclampsia. Rest of the cases were cases of eclampsia (Table 1 and Table 2).

There were 3 maternal deaths in the HELLP syndrome group along with 5 perinatal deaths. There were 28 maternal deaths in the non HELLP syndrome group. 
Table 1. Showing age, parity, gestational age, and mean arterial pressure with the perinatal outcome.

\begin{tabular}{cccccccccc}
\hline $\begin{array}{c}\text { Case } \\
\text { No. }\end{array}$ & $\begin{array}{c}\text { Age } \\
\text { (yrs.) }\end{array}$ & Parity & $\begin{array}{c}\text { Gestational } \\
\text { age weeks }\end{array}$ & $\begin{array}{c}\text { Eclampsia/severe } \\
\text { pre-eclampsia }\end{array}$ & $\begin{array}{c}\text { Mean } \\
\text { arterial } \\
\text { pressure }\end{array}$ & $\begin{array}{c}\text { Urine } \\
\text { albumin }\end{array}$ & $\begin{array}{c}\text { Mode of } \\
\text { delivery }\end{array}$ & $\begin{array}{c}\text { Perinatal } \\
\text { outcome } \\
\text { survival/death }\end{array}$ & $\begin{array}{c}\text { Baby } \\
\text { weight in Column 1 } \\
\text { kgs }\end{array}$ \\
\hline 1 & 22 & 0 & 37 & Eclampsia & 146.00 & $3+$ & LSCS & Survived & 2.4 \\
2 & 18 & 1 & 38 & Eclampsia & 106.00 & $2+$ & Vaginal & Died & 2.3 \\
3 & 21 & 2 & 24 & Eclampsia & 118.00 & $2+$ & Vaginal & Died & 0.7 \\
4 & 32 & 0 & 37 & Severe pre-eclampsia & 133.00 & $2+$ & Vaginal & Survived & 2.1 \\
5 & 24 & 0 & 26 & Severe pre-eclampsia & 120.00 & $3+$ & Vaginal & Died & 1 \\
6 & 22 & 0 & 36 & Eclampsia & 127.00 & $2+$ & LSCS & Survived & 3.1 \\
7 & 19 & 0 & 36 & Eclampsia & 147.00 & $1+$ & Vaginal & Died & 3.4 \\
8 & 20 & 0 & 33 & Eclampsia & 147.00 & $2+$ & Vaginal & Died & 1.4 \\
\hline
\end{tabular}

Table 2. Table showing laboratory parameters and maternal outcome.

\begin{tabular}{|c|c|c|c|c|c|c|c|c|c|c|}
\hline $\begin{array}{c}\text { Case } \\
\text { No. }\end{array}$ & $\begin{array}{c}\text { HB } \\
\text { gm/dl }\end{array}$ & $\begin{array}{l}\text { Platelets } \\
\times 10^{5}\end{array}$ & $\begin{array}{l}\text { AST } \\
\text { IU/L }\end{array}$ & $\begin{array}{l}\text { ALT } \\
\text { IU/L }\end{array}$ & $\begin{array}{l}\text { LDH } \\
\text { IU/L }\end{array}$ & $\begin{array}{l}\text { B.urea } \\
\text { Mg/dl }\end{array}$ & $\begin{array}{c}\text { Serum } \\
\text { creatinine } \\
\text { mg/dl }\end{array}$ & Maternal complications & Survival/death & Cause of death \\
\hline 1 & 8 & 1.36 & 111 & 164 & 623 & 45.3 & 0.73 & Nil & Survived & Nil \\
\hline 2 & 8 & 1.2 & 498 & 354 & 700 & 86.3 & 1.23 & CVA & Death & Cerebral haemorrhage \\
\hline 3 & 10.6 & 0.94 & 197 & 174 & 720 & 46 & 1 & Nil & Survived & Nil \\
\hline 4 & 11.2 & 1.4 & 367 & 129 & 785 & 34 & 0.93 & Nil & Survived & Nil \\
\hline 5 & 6 & 0.8 & 60 & 210 & 1024 & 103 & 2.8 & DIC, ARF, HELP syndrome & Death & DIC, HELLP syndrome \\
\hline 6 & 10.8 & 0.68 & 600 & 432 & 1985 & 68.6 & 0.96 & Rt hemiparesis & Survived & Nil \\
\hline 7 & 10.6 & 1.21 & 551 & 229 & 2067 & 35.1 & 1.2 & Nil & Survived & Nil \\
\hline 8 & 10.1 & 0.8 & 65 & 210 & 14196 & 20.6 & 0.9 & HELLP, DIC & Death & HELLP DIC \\
\hline
\end{tabular}

The incidence of HELLP syndrome is reported to be $10 \%$ to $20 \%$ in cases of pre-eclampsia and is seen in $0.5 \%$ to $0.9 \%$ of all pregnancies. Our study demonstrated a $3.36 \%$ incidence of the syndrome in a population of 238 cases of pre-eclampsia and eclampsia which is remarkably low in comparison to the reported statistics. Even on including the four patients who fulfilled two criteria out of three, the percentage was 5.04\%.

In the eight patients that showed all three parameters of HELLP syndrome, 4 patients had platelet counts between 100,000 and 150,000 (class 3) and 4 had platelet counts between 50,000 and 100,000 (class 2). None had a platelet count less than 50,000. Two patients showed platelet counts between 100,000 and 150,000 with ALT > $40 \mathrm{IU}$ but no elevation of LDH. Two patients had high LDH and ALT $>70 \mathrm{IU}$ but the platelet counts were in the normal range.

Looking at the elevation of liver enzymes in the study population, however, 74 patients out of the 238 showed ALT $\geq 40$ IU which came to $30.96 \%$. Of these, 29 had ALT $\geq 70$ IU which came to $12.13 \%$. AST level was $\geq 40$ IU in 149 cases and was $\geq 70 \mathrm{IU}$ in 48 patients or $62.34 \%$ and $20.08 \%$ respectively.

30 patients or $12.55 \%$ had platelet counts below 150,000 . Elevated LDH $\geq 600$ IU was seen in 15 cases i.e. $6.27 \%$.

As the derangement of ALT was the parameter showing the most remarkable elevation in our study population we tried to find out how and if it correlated with the derangement of the other laboratory parameters. A Spearmann's correlation was applied to determine the correlation of other variables with the levels of ALT. Spearmann's correlation was applied as on running a normality test the distribution of variables (levels of ALT) is skewed (Skewness coefficient $=4.431$, standard error $(\mathrm{SE})$ of skewness $=0.158)$. 
- The levels of LDH showed a very weak positive correlation with the values of ALT. ( $(\check{s}=0.079, p$ value $=$ 0.226 );

- The platelet count showed a very weak negative correlation with the levels of ALT ( $\mathrm{rs}=0.000496, p$ value $=$ 0.994);

- Levels of AST showed a strong positive correlation with the levels of ALT ( $\mathrm{rs}=0.686, p$ value $<0.001$ );

- The levels of blood urea showed a weak positive correlation with ALT ( $\mathrm{rs}=0.236, p$ value $<0.001)$;

- The levels of serum creatinine showed a very weak positive correlation with ALT ( $\mathrm{rs}=0.140, p$ value $=$ 0.031 );

- The level of Hemoglobin showed a very weak positive correlation with the ALT levels ( $\mathrm{rs}=0.109, p$ value $=$ 0.093);

- The level of hemoglobin showed a very weak and insignificant correlation with LDH ( $p$ value $=0.292)$;

- On correlating the ALT levels with the mean arterial pressure no correlation was found ( $p$ value $=0.936$ ).

Fischer's exact test was applied to find out the association between HELLP syndrome and maternal mortality and we found no significant association of HELLP syndrome with maternal and perinatal mortality ( $p$ value $>$ 0.05 ). For comparison of maternal mortality in HELLP and non HELLP cases $\chi^{2}=4.377, \mathrm{df}=1, p$ value $=$ 0.071 . For comparison of perinatal mortality in HELLP and non HELLP $\chi^{2}=3.320, \mathrm{df}=1, p$ value $=0.079$.

\section{Discussion}

Our study shows a remarkably low incidence of HELLP syndrome in our study population as compared to the studies conducted on Caucasian populations [9]. It also shows that derangement in one laboratory parameter does not lead to a significant derangement of the other parameters. Derangement of laboratory parameters was seen in the population but occurred independent of each other so that on taking all the three parameters for HELLP, only 8 cases conformed to the criteria. Rising levels of ALT which are suggestive of hepatic injury as a result of ischemia appear to show a trend but do not correlate significantly with falling platelet counts or rising levels of LDH suggestive of hemolysis. The level of hemoglobin would be expected to fall with rising hemolysis but no such trend was seen in our study population. A probable explanation would lie in the fact that there is hemoconcentration in cases of pre-eclampsia [10] and the effect of hemolysis, if any, would be offset by the effect of hemoconcentration. Nutritional anemia is very common in our population and hemoglobin levels would also tend to be affected by it [11].

There is also a weakly positive but significant correlation between the derangement of the liver functions and the derangement of blood urea and serum creatinine in our population suggesting simultaneous micro angiopathy in the kidneys as well as the liver.

The syndrome of hemolysis, elevated liver enzymes and low platelets has been observed to be significantly higher in the Caucasian population, in those with delayed diagnosis of pre-eclampsia and in nulliparous patients [12]. In our population 6 out of the eight patients diagnosed with complete HELLP syndrome were para 0 , one patient was para 1 and one was para 2, which showed a higher incidence in nulliparous patients. Out of the eight cases with HELLP syndrome, eclampsia occurred in 6 cases while the remaining two had severe pre-eclampsia. Three patients out of eight died. Of the three who died two died of DIC and one died of a cerebral hemorrhage. Of the rest, one survived with right sided hemi paresis. Abruptio placentae and renal failure which were common complications of HELLP syndrome in other studies were not seen in our cases with HELLP syndrome despite evidence of deranged renal function. There were five perinatal deaths in the group of HELLP syndrome.

HELLP syndrome is seen to occur in cases of pre-eclampsia in $10 \%$ to $20 \%$ of cases though in 15 to 20 percent cases of HELLP syndrome no history of antecedent hypertension or proteinurea may be present [13]. The etiology of pre-eclampsia may have genetic and immunological origins and the etiology of HELLP syndrome may be closely linked with it. Any patient of pre-eclampsia may develop HELLP syndrome along with asymmetrical IUGR which is a resultant of the placental pathology.

The immune response at the maternal fetal interface may lead to insufficient remodeling of spiral arterioles and the arterioles retain their muscular coat resulting into a high resistance system. There is an imbalance in the angiogenic factors and an oxidative stress leading to inflammation. The resultant placental insufficiency leads to release of placental factors in the maternal circulation. The resultant inflammatory response leads to a generalized endothelial dysfunction with activation of complement. The dysfunctional endothelium leads to adherence of platelets and hemolysis leading to ischemic injury to the involved organs, especially liver and results in preeclampsia and HELLP syndrome [4] [14]. 
The fetus expresses antigens of paternal origin which are foreign to the mother's immune system. Dysregulation of antigens at the maternal fetal interface may lead to pre-eclampsia and HELLP syndrome. This may be supported by the fact that adequate exposure to paternal antigens in seminal fluid prior to the first pregnancy seems to prevent pre-eclampsia indicating an immunological memory which is most likely stored in T cells [15][17].

The etiology of the disease cannot be attributed solely to genetic causes and interaction between genetic and environmental factors may be involved in the pathogenesis. Nutritional deficiencies such as those of protein, calcium, vitamin C and vitamin D may play a role [18] [19].

Why our population showed such a low incidence of HELLP can be explained in terms of the racial differences and probably also on the basis of dietary differences. Many genes have been implicated in the etiology of HELLP syndrome, such as the STOX1 gene, Syncytin Envelope Gene, Mannose Binding Lectin (MBL) gene polymorphism, Factor V leiden mutation, MTHFR deficiency [12]. Vascular endothelial growth factor (VEGF) and mutations of Angiotensin converting enzyme (ACE) have also been implicated in the pathogenesis [20].

Most of these studies have been conducted on Caucasian patients and our population which is a local population from Jabalpur and surrounding areas may be having a genetic and nutritional profile entirely different from the Caucasians. Our population shows a high incidence of pre-eclampsia and eclampsia but the derangements conforming to complete HELLP are very low as compared to the western population. Though pre-eclampsia and HELLP syndrome are closely linked, there seems to be an etiological factor for HELLP which is separate and has a significantly low incidence in our population. It would be pertinent to study the genetic profile as well as the dietary factors in our patients to look for etiological factors. Our population is predominantly vegetarian and the diet is low in animal protein. This may point towards an immunological factor involved in the pathogenesis. Our climate is tropical which is hot and humid, entirely different from the climate of European countries and the environment may also have a role to play in the complexities of the etiopathogenesis.

The derangement of ALT had no correlation with the mean arterial pressure suggesting that the hepatic dysfunction was independent of the level of blood pressure.

The level of ALT was the parameter showing elevation in the highest percentage of the population but the platelet count did not show a correlating fall with it and the levels of LDH also did not show a remarkable correlation, suggesting that the liver dysfunction was a separate clinical entity. The parameters of renal function showed a weak but significant correlation with the derangement of liver function suggesting that the micro angiopathy affected both the organs, though the renal dysfunction in our population did not reach the extent of renal failure. Further in depth studies of our population are required to study the genetic, dietary and environmental influences in the etiology of HELLP syndrome and also to study at what point the etiopathogenesis of HELLP though appearing similar and closely linked diverges from that of pre-eclampsia.

\section{Conclusion}

We observed a significantly low incidence of HELLP syndrome i.e. $3.36 \%$ in our study population. There was remarkable liver dysfunction in $12.3 \%$ of patients which had no correlation with the level of blood pressure and also had a weak correlation with other laboratory parameters. The correlation was weak but statistically significant with the parameters of renal function showing simultaneous pathology in both organs though, remarkably, the renal dysfunction did not progress to the extent of acute renal failure in any of our cases. Further research may be required to investigate at what point the etiology of HELLP syndrome differs from that of pre-eclampsia and a study of the genetic as well as nutritional profile of our patients may offer a clue in this regard.

\section{Conflict of Interest}

The authors would like to state that no conflict of interest exists in this study.

\section{References}

[1] Sibai, B.M., Ramadan, M.K., Usta, I., Salama, M., Mercer, B.M. and Friedman, S.A. (1992) Maternal Morbidity and Mortality in 442 Pregnancies with Hemolysis, Elevated Liver Enzymes, and Low Platelets (HELLP Syndrome). Intensive Care Medicine, 18, 274-277.

[2] Boujdaria, R., Nouira, S., Abroug, S., Souissi, M. and Najjar, M.F. (1992) Hellp Syndrome: Incidence and MaternalFetal Outcome-A Prospective Study. Intensive Care Medicine, 18, 274-277. http://dx.doi.org/10.1007/BF01706472 
[3] Curtin, W.M. and Weinstein, L. (1999) A Review of HELLP Syndrome. Journal of Perinatology, 19, 138-143. http://dx.doi.org/10.1038/sj.jp.7200165

[4] Kappler, S., Ronan-Bentle, S. and Graham, A. (2014) Thrombotic Microangiopathies (TTP, HUS, HELLP). Emergency Medicine Clinics of North America, 32, 649-671. http://dx.doi.org/10.1016/j.emc.2014.04.008

[5] Riedl, M., Fakhouri, F., Le Quintrec, M., Noone, D.G., Jungraithmayr, T.C., Fremeaux-Bacchi, V. and Licht, C. (2014) Spectrum of Complement-Mediated Thrombotic Microangiopathies: Pathogenetic Insights Identifying Novel Treatment Approaches. Semin Thromb Hemost, 40, 444-464. http://dx.doi.org/10.1055/s-0034-1376153

[6] Shenkman, B. and Einav, Y. (2014) Thrombotic Thrombocytopenic Purpura and Other Thrombotic Microangiopathic Hemolytic Anemias: Diagnosis and Classification. Autoimmunity Reviews, 13, 584-586. http://dx.doi.org/10.1016/j.autrev.2014.01.004

[7] Haram, K., Svendsen, E. and Abildgaard, U. (2009) The HELLP Syndrome: Clinical Issues and Management. A Review. BMC Pregnancy Childbirth, 9, 8. http://dx.doi.org/10.1186/1471-2393-9-8

[8] M artin Jr., J.N., Rose, C.H. and Briery, C.M. (2006) Understanding and Managing HELLP Syndrome: The Integral Role of Aggressive Glucocorticoids for Mother and Child. American Journal of Obstetrics \& Gynecology, 195, 914934. http://dx.doi.org/10.1016/j.ajog.2005.08.044

[9] Padden, M.O. (1999) HELLP Syndrome: Recognition and Perinatal Management. American Family Physician, 60, 829-839.

[10] Heilmann, L. (1987) Blood Rheology and Pregnancy. Baillière's Clinical Haematology, 1, 777-799. http://dx.doi.org/10.1016/S0950-3536(87)80024-0

[11] Kapil, U. and Bhadoria, A.S. (2014) Prevalence of Folate, Ferritin and Cobalamin Deficiencies amongst Adolescent in India. Journal of Family Medicine and Primary Care, 3, 247-249. http://dx.doi.org/10.4103/2249-4863.141619

[12] Haram, K., Mortensen, J.H. and Nagy, B. (2014) Genetic Aspects of Preeclampsia and the HELLP Syndrome. Journal of Pregnancy, 2014, Article ID: 910751. http://dx.doi.org/10.1155/2014/910751

[13] Audibert, F., Friedman, S.A., Frangieh, A.Y. and Sibai, B.M. (1996) Clinical Utility of Strict Diagnostic Criteria for the HELLP (Hemolysis, Elevated Liver Enzymes, and Low Platelets) Syndrome. American Journal of Obstetrics and Gynecology, 175, 460-464.

[14] Alasztics, B., Kukor, Z., Pánczél, Z., Valent, S. (2012) The Pathophysiology of Preeclampsia in View of the TwoStage Model. Orvosi Hetilap, 153, 1167-1176. http://dx.doi.org/10.1556/OH.2012.29415

[15] Saftlas, A.F., Rubenstein, L., Prater, K., Harland, K.K., Field, E. and Triche, E.W. (2014) Cumulative Exposure to Paternal Seminal Fluid Prior to Conception and Subsequent Risk of Preeclampsia. Journal of Reproductive Immunology, 101-102, 104-110. http://dx.doi.org/10.1016/j.jri.2013.07.006

[16] Triche, E.W., Harland, K.K., Field, E.H., Rubenstein, L.M. and Saftlas, A.F. (2014) Maternal-Fetal HLA Sharing and Preeclampsia: Variation in Effects by Seminal Fluid Exposure in a Case-Control Study of Nulliparous Women in Iowa. Journal of Reproductive Immunology, 101-102, 111-119. http://dx.doi.org/10.1016/j.jri.2013.06.004

[17] Robertson, S.A., Bromfield, J.J. and Tremellen, K.P. (2003) Seminal "Priming" for Protection from Pre-Eclampsia-A Unifying Hypothesis. Journal of Reproductive Immunology, 59, 253-265. http://dx.doi.org/10.1016/S0165-0378(03)00052-4

[18] Vasiljević, N., Vasiljević, M. and Plećas, D. (1996) The Role of Nutritional Factors in Pre-Eclampsia and Eclampsia. Srpski Arhiv za Celokupno Lekarstvo, 124, 156-159

[19] Roberts, J.M., Balk, J.L., Bodnar, L.M., Belizán, J.M., Bergel, E. and Martinezy, A. (2003) Nutrient Involvement in Preeclampsia. Journal of Nutrition, 133, 1684S-1692S.

[20] Lam, C., Lim, K.H. and Karumanchi, S.A. (2005) Circulating Angiogenic Factors in the Pathogenesis and Prediction of Preeclampsia. Hypertension, 46, 1077-1085. http://dx.doi.org/10.1161/01.HYP.0000187899.34379.b0 